\title{
The relationship between persons with mental health problems and their dogs: A qualitative study within a nursing perspective
}

\author{
Siri Merete Skjørestad, Berit Johannessen \\ Institute of Health and Nursing Science, University of Agder, Norway \\ Correspondence: Berit Johannessen. Address: Nordre Hovedgårdsvei 25, 4621 Kristiansand, Norway. Telephone: \\ 473-814-1869. Email: Berit.Johannessen@uia.nol. \\ Received: May 22, 2012 \\ DOI : $10.5430 /$ jnep.v3n1p130 \\ Published: January 1, 2013 \\ URL: http://dx.doi.org/10.5430/jnep.v3n1p130
}

\section{Abstract}

Background: There is an increasing number of people with mental health disorders in the Western world. The most common traditional therapies are conversational therapy and medications. One alternative to traditional therapies is Anthrozoology. Anthrozoology treats the interaction between people and animals, and it shows that animals can be a great contributor to human health and wellness.

Purpose: The purpose of this study was to examine how people with mental health disorders experience owning a dog.

Methods: The chosen design was qualitative, and the methods were interviews and observations of five informants with their dogs. The analysis was conducted with systematic text-condensation.

Results: Four main categories emerged: 1. Increased social and physical activity. 2. Supporting relationship. 3. Increased responsibility. 4. Varied response from nurses.

Conclusion: People suffering from mental health disorders experience a strong and healing attachment to their dogs. This can be explained by different theories. Nurses require knowledge of the dog's positive impact on people with mental health disorders.

\section{Key words}

Pet therapy, Mental health disorder, Healing relationship, Anthrozoology

\section{Introduction}

An increasing number of people in the Western world have mental health problems. In Norway, one in every five people has a mental-health disorder at any given time, placing a heavy economic burden on society ${ }^{[1]}$. The most common disorders are anxiety and depression, and the most common therapies are conversational therapies and medication ${ }^{[1]}$.

Anthrozoology examines the interaction between people and animals and has shown that animals can contribute greatly to human health and well-being ${ }^{[2]}$. Although anthrozoology has been studied internationally for some time, it is a new discipline in Norway. 
The founder of nursing, Florence Nightingale, claimed in her Notes on nursing that "small animals were excellent companions for the sick, for long chronic cases especially". Today animal assisted therapy is defined as complementary/ alternative therapy in nursing ${ }^{[3]}$.

There is an increasing tendency for Norwegians to have dogs as pets, and Norway's population of five million people has approximately $400,000 \mathrm{dogs}{ }^{[4]}$. Animals have been used in therapy since the 9th century, especially in mental-health care ${ }^{[5]}$. In modern times, pets as therapy was introduced by Boris Levinson, who brought his own dog into therapy sessions in the $1960 \mathrm{~s}{ }^{[4]}$. Further studies since that time have shown that animals can reduce blood pressure, pulse, respiration, stress hormones, pain, stress, and anxiety ${ }^{[5]}$. Animals can also increase the hormones associated with relaxation and well-being ${ }^{[6]}$, physical activity ${ }^{[7]}$, and social contact with other humans ${ }^{[5,8]}$.

Most of these studies have explored how animals can be introduced into institutions or how therapists can use their own animals in therapy, so-called 'animal-assisted therapy' ${ }^{[5,9]}$.

Wisdom et al. ${ }^{[10]}$ examined how people with mental-health disorders benefited from owning a pet in terms of their recovery, interviewing 177 people with mental-health disorders. They found that pets were a form of therapy and contributed empathy by understanding their owners and responding to their feelings. They also found that not only did the animal itself provide social support; it also increased the respondent's social contact with other people, and could also substitute for family members. Wisdom et al. also showed that the respondents' control of their pets and their relationships with their pets empowered them and increased their self-efficacy/self-worth, although in some cases, the responsibility combined with other stress factors became too much, sometimes leading to depression. The loss of an animal could also induce depression ${ }^{[10]}$.

Two main theories have been proposed to explain why humans so easily bond with pets and want to take care of them. The first is the biophilia hypothesis, proposed by Wilson in the 1960s, which claims that humans have an inborn predisposition to affiliate with or attend to natural-like elements and processes ${ }^{[15]}$.

The other theory that has emerged from recent research is that contact with animals causes humans to release the peptide hormone oxytocin, just as they do when they care for or nurse an infant ${ }^{[16]}$. This hormone is known to reduce stress and anxiety. It can also create a feeling of relaxation and wellness, and is responsible for the feeling of connectedness between a mother and infant. It seems that this hormone is responsible for the bonding and attachment between humans and animals $^{[17]}$.

Wisdom et al. ${ }^{[10]}$ suggested that health-care providers should be aware of the relationships between person with mental health problems and their animals, and that further research into this is warranted. These factors, together with the lack of qualitative nursing research on the subject, underpin the aim of this study: to examine how people with mental-health problems experience owning a dog. Other research questions were also addressed: How does the relationship with a dog influence the health of people with mental-health problems? How do people with mental-health problems experience nurse's view of their relationships with their dogs?

\section{Methods}

The study design was qualitative and the methodological tools used were interviews and observations.

\subsection{Sample}

The sample selection started in a local community psychiatric health-care service, where nurses informed the patients about the study. The nurses made contact with four patients with mental-health disorders who wanted to participate. Three of these four completed the study. One patient was recruited by informal contact, and one was included on the snowball- 
inclusion principle ${ }^{[18]}$. In total, there were five respondents (four women and one man) between the ages of 29 and 70 years. The respondents had different psychiatric diagnosis as for instance schizophrenia, bipolar disorder, major depression and anxiety. They lived in three different small cities in Norway.

\subsection{I nterviews}

During the interviews, a one-page semistructured interview guide was used. This had five different themes, with varying numbers of questions. The interview guide was based on previous research, primarily on the findings of Wisdom et al. ${ }^{[10]}$. The categories were:

1) You-demographic information

2) The dog-information about the dog and the relationship with the dog

3) Positive sides to having a dog

4) Negative sides to having a dog

5) Nurses-how they may or may not have taken the relationship into account

The guide ended with a summing-up question so that the respondent could have the last word ${ }^{[19]}$. The interviews lasted approximately $30 \mathrm{~min}$ each, and were all tape-recorded and then transcribed by the author. All the interviews took place at the homes of the participants so that the dog could be present for observation.

\subsection{Observations}

The observations were simple, and focused primarily on the relationship between the dog and the respondent: how they interacted (communication and behavior) and how the dog appeared (if it was clean and healthy).

\subsection{Ethical considerations}

Before the study was conducted, it was approved by the Ethical Committee of the University of Agder and the Norwegian Social Science Data Services ${ }^{[20,22]}$. All the participants signed a voluntary, informed consent form, and the information about the participants was treated as confidential ${ }^{[20,21]}$. Electronic information was coded with TrueCrypt, and all material was locked in two different cases so that the written consent, name, and code key were held separately. After the analysis, the information presented was anonymized.

\subsection{Analysis}

The analysis was conducted with Malterud's systematic text condensation ${ }^{[22]}$, which is a modified version of Giorgi's phenomenological method. This means that all the transcribed material (which included all observations) was read through, and from this reading, intuitive themes emerged and were written down. Meaning units were then extracted from the interviews and categorized under the themes in a new document. The material was printed, and the data were manually extracted and systemized into subcategories. The meaning of each subcategory was summarized. Finally, all the interviews were read again to validate the results ${ }^{[22]}$.

\section{Results}

The main categories were:

1) increased social and physical activity;

2) supporting relationship;

3) increased responsibility; 
4) varied responses from nurses.

These categories will be presented and illustrated with quotes, and then discussed in the next section.

\subsection{I ncreased social and physical activity}

The subjects reported that their dogs inspired or "forced" them to go outside, even though they did not want to. Most of the respondents spent much time outside with their dogs, and at most, one respondent walked the dog for four hours every day: "If I hadn't had the dog, I don't think I would have seen so much great nature at all!" The respondents knew that physical activity could positively affect their mental health, and some of them had considered this when they decided to buy a dog.

Because they had to be outside, the respondents also met other people to whom they talked, and in some cases, this resulted in close friendships. One subject said: "I believe that all people who have trouble with themselves need an animal...To get out, because I think many just lock themselves up, I almost did... when you have a dog, you have to get out, and so you have to be social...you can't choose...". Another respondent said that her friend had noticed that she had changed as a person. Before she got her dog, she was isolated and lonely, but after she had the dog, she went out and met other people. A third respondent also reported this when she said: "Because of the anxiety, I was almost always inside alone, and when my friends asked me to come out with them, I didn't dare. So the dog has helped me a lot. I just have to go out, and everything has been much better for me...". Some respondents reported making new acquaintances because of the dog: one was invited to the home of a neighbor, who had a dog kennel; another said that the neighbors joined her for a smoke and a cup of coffee on the stairs outside, watching the dogs play.

All the subjects talked about how children stopped to pat the dog and talk to it. One of the respondents had even gone to an exhibition with her dog, where she met many people talking about dogs. Another of the respondents reflected upon this: "Socially, the dog has meant a lot to me, I always get to talk to people, for instance when she is sitting outside the shop waiting for me, there is always someone there who wants to talk to me about my beautiful dog."

\subsection{Supporting relationship, love, and confidence}

All the subjects felt a strong connection to their dog, and they called it a family member. In several cases, they reported that the dog meant as much to them as their children and that they could not imagine life without it. The word "love" was often used. Observations revealed that the way they talked to the dog was very similar to the way we talk to children, with a softer voice and easy words, often repeating them. Three of the respondents said that their dogs slept beside them in bed at night, and the other two allowed the dog to sleep on the floor of their bedrooms.

The respondents reported that it was hard to be away from the dog, even for short periods, and that losing the dog would be like losing a family member. In one case, the connection was so strong that it stopped the respondent taking her life: “...in periods of suicidal thoughts, and before I got married and had children like now, she was the only thing stopping me taking the step, I didn't just give up, I thought my family would be affected, but they would move on. I got this dog, it's my responsibility, I can't run from that...it's intense to say it, but I think she saved my life several times! Kept me normal or what do you say?...kept my head above water...."

All the respondents talked with their dogs a great deal, sometimes having long conversations, and they emphasized the fact that their dogs seemed to love them no matter what. One of them said: "They never tell anybody, they don't judge, they just love."

Going outside and meeting people often affected the respondents in a positive way, as one of them said: "I have gained confidence and self-control, and I dare to do things. I became a more positive, brave, and outgoing person after a got my dog." Another subject said: "She (the dog) has very much influenced my way of being, in a positive way." The dog prompted positive feelings; the respondents could not simply sit down and feel miserable. When the dog came to them, 
wagging its tail, they felt happy, or the dog claimed their attention and time. As one of the women said: "They give you a lot to think about, but that's maybe a positive thing. It caused the inward focus on myself to disappear, and gave me something else to focus on!"

To have the dog beside them in difficult times gave the respondents feelings of security, comfort, and unconditional love. One subject said that she used to be afraid of being alone and afraid of the dark, but the dog follows her everywhere and she is no longer afraid. Another described a situation that occurred in hospital: "My daughter came to see me, and I asked about the dog. She brought the dog from the car and it was like heaven opened up: the dog jumped and licked me all over. Oh, it was just like she cried when she saw me! It was such a proof of love."

All the respondents perceived that their dogs reacted actively to their emotions. If they felt sad or depressed, the dogs reacted with behavior the respondents called "comfort". When comforting them, the dogs laid their heads in their owners' laps, started to become clingy, or tried to lick away their tears, or "communicated" verbally by whimpering. One of the subjects reported how her dog jumped over a $2 \mathrm{~m}$ high fence just to comfort her when she had an anxiety attack. Another respondent, who had diabetes, also reported that on several occasions, the dog had alerted her that she was at risk of hypoglycemia before she felt it herself.

\subsection{I ncreased responsibility}

The ownership of a dog also entails responsibility, and the respondents emphasized that having a dog is a great responsibility. One of them said: "You have the responsibility for-what shall I call it?-for another life. It is a great responsibility." The dogs must be kept in proper condition and they require daily attention. As one subject said: "They need food, water, care...like this dog needs grooming, they need attention, and they must have love...". The respondents stressed that not everybody should get a dog, especially if they cannot look after it properly, and that having a dog claims a lot of time. When asked about the negative aspects of dog ownership, they responded that the dogs hindered them taking vacations, but they all stated that this really did not matter. They would rather have the dogs. The economic side of owning a dog was also mentioned, but as one subject concluded: “...but the dog is worth it!”

\subsection{Varied responses from community health nurses}

Three of the respondents reported that community health nurses were considerate regarding the fact that they had a dog. The nurses expressed this by greeting the dog when they came on their usual visits and supporting the respondent by confirming the positive effects the dog had on its owner. One of the nurses even advised against giving away the dog because of the positive effect it had on the respondent. The other two respondents missed getting positive support from their caregivers regarding their relationships with their dogs. The subjects would have liked their nurses to focus more on the dog and to use it actively in social therapy. One respondent proposed dog-training classes as a meaningful alternative to standing in a shop for 20 min, which was the usual exposure therapy. However, this was not permitted.

One subject also told the story of an insult from social services, who said that she should put the dog to sleep if she did not have enough money for the rent. She said she was shocked to hear this because the dog was the only stable thing in her life.

It was also important for two other respondents that the dog could come with them when they had to move into public housing, although it is often forbidden to have dogs in these apartments.

\section{Discussion}

Social isolation and loneliness as the result of anxiety are well-recognized problems for people with mental-health disorders. Breaking the vicious cycle of not going out and lacking practice in social skills, leading to increasing anxiety, is a goal of exposure therapy, widely used in psychiatric nursing ${ }^{[25,26]}$. It is confirmed by the findings of Wisdom et al. ${ }^{[10]}$ that subjects with dogs experienced more social interactions with other humans and an increased appreciation of everyday 
life. It was apparent in our study that some of the respondents were very clear on this point. They knew that they found it difficult to get out of the house and meet people, and this was one of the reasons behind their initial decision to get a dog. They actively acquired their dogs to provide therapy for themselves, and they found that the dogs gave them the support they needed.

Wisdom et al. ${ }^{[10]}$ also noted that the animals actively sought out their owners when they were feeling bad, which was confirmed in this study. When the owners felt bad, their dogs gave them positive support and stopped their symptoms escalating. To experience love and support is healing, and when the respondents knew that their dogs needed them, they seemed to find coping resources within themselves. One of them even said that the close relationship to her dog had stopped her committing suicide. Considering suicide can be described as a very stressfull situation, but relationship with a dog can help the patient cope. To give support and help people cope is an important part of nursing care.

The respondents stressed that getting outdoors was important, which may be a Norwegian tendency. Fugelli and Ingestad found that compared with other nationalities ${ }^{[23]}$, Norwegians reported that their health was strongly linked to the opportunity to be outdoors and explore nature. In this study, the respondents spent a great deal of time outdoors with their dogs. This meant that they got exercise when they owned a dog, and exercise is itself a well-documented preventive and therapeutic strategy for mental-health problems ${ }^{[24]}$.

In this study, the respondents particularly emphasized the dog's welfare. Their opinions of what a dog needs were consistent with the ethical considerations published by the Norwegian Kennel Club ${ }^{[27]}$. They spent a great deal of time with their dogs, and their dogs imposed routine and structure on their daily lives, which may have been beneficial. This emphasizes the fact that having a dog is a commitment, but may also benefit those with mental-health problems. The respondents found that their dogs increased their social interactions and reduced their isolation, which is therapeutic for people with mental health disorders, who can easily become isolated ${ }^{[10]}$.

The fact that the dogs reacted to their owners' feelings may be explained by the study of Mills et al. ${ }^{[14]}$, who found that dogs, like humans, focus on the left sides of people's faces when they look at them. This is the main area in which we express our feelings. Remarkably, dogs actually understand and interact with humans to help lighten their moods and provide comfort. This shows that dogs have interspecies empathy, something that is seldom found in other species. The experience of being seen and understood may be healing for people with mental-health problems and prevent the further development of their disorders.

The connection and attachment to their dogs felt by the respondents cannot merely be explained by the biophilia hypothesis, because if a genetic predisposition is solely responsible for this attachment, we would all feel an attachment to the whole of nature, not just to the animals we encounter, but also to the trees and plants. Most of the subjects also had other animals, but these were not considered as significant as the dogs. This attachment may be explained by the oxytocin theory. If the respondents experience a release of oxytocin when in contact with their dogs, they may develop the same attachment to the dog as to a child, which is consistent with their respondents. Miller et al. ${ }^{[16]}$ found that this effect was only significant in women, although in the present study, the male participant possibly seemed even more attached to his dogs than the rest of the group. This may be attributable to the fact that he had a smaller human network, but if not, oxytocin alone cannot explain the attachment.

In nursing care, the value attributed to dog ownership varies. The level of understanding of this phenomenon among nurses and other health-care workers has been poorly explored. Whether health-care providers include animals in therapy is quite incidental, and whether they have heard of the benefits of owning a dog is unclear. This may be because animal-assisted therapy is rare in Norway and is not included in the education of nurses and other health-care workers. There is lack of knowledge about animal assisted therapy among health-care workers. But also internationally there is lack of knowledge about animal assisted therapy among health-care workers. Serpell ${ }^{[28]}$, a leading authority on human-animal bonds, views the neglect of this topic as a legacy of the anthropocentrism that has dominated Western thinking and mental health Published by Sciedu Press 
paradigms. The dismissive assumption, "It's only an animal," has blinded many to the significance of these bonds, but that by expanding our vision beyond this prejudiced mindset, hopefully, we can enrich clinical practice through a more holistic and open-minded view of the potential contribution of animal bonds to human healing and well-being.

The respondents stressed that they take their attachment to their dogs very seriously, so nurses should also do so. They also suggested how this could be done, and dog owners with mental-health problems could make a worthwhile contribution if health-care providers were receptive to it.

\section{Critical comments}

Although these findings are supported by the literature ${ }^{[5,10]}$, the study sample was small, so conclusions cannot be extrapolated to the whole population of dog owners with mental-health problems ${ }^{[18]}$. It must also be kept in mind that owning a dog is not appropriate for everybody and should not be taken lightly, which was emphasized by the respondents. The positive effects of dog ownership also require that the animal is cared for properly, and that the owner really wants the animal and is not afraid of it ${ }^{[10,28]}$.

\section{Conclusions and implications}

People suffering from mental-health disorders experience a strong attachment to their dogs, and this attachment can be healing. Their mental health is improved by getting out of the house, meeting other people, and being physically active. Dogs give love and comfort, and can read and respond to emotions, which is therapeutic for the mentally ill. Although having a dog can be hard work, it seems to benefit people with mental-health disorders. The attachment can be explained by different theories, although no clear conclusions have yet been drawn about why people become so attached to their dogs. Nevertheless, this kind of relationship should be considered when working with people with mental-health problems, and can be an asset in therapy. Previous research has explored many ways to include animals in therapy. Further research should explore the option of using the client's own dog in therapy. In this context, people with mental-health disorders seem to have much to contribute. We also recommend that institutions and mental-health-care services initiate measures to make nurses more aware of the healing relationships between people and animals.

\section{Conflicts of interest}

The authors report no conflicts of interest in this study. No financial support was received for the study or the writing of this article.

\section{References}

[1] Norwegian council of mental health. Mental health in Norway [Internet]. 2009 06.01.2010 [cited 2010 13. september]. Available from: http://www.psykiskhelse.no/index.asp?id=29617.

[2] International Society of Anthrozoology [Internet]. Homepage. 2011 [cited 2011 09. mars 2011]. Available from: http://www.isaz.net/.

[3] Institute, T.N.P.H., The book of Infection Control, in Chapter 21 - Bites and Infection. 2010.

[4] Snyder,M., Lindquist,R. (ed). Complementary/Alternative Therapies in Nursing. Springer Publishing Company. 2006; $175-187$.

[5] Morrison, M.L., Health Benefits of Animal Assisted Interventions. Complementary Health Practice Review. 2007 ; 12 (1): 51-62.

[6] Baun, M., R. Johnson, and B. McCabe, Human-Animal Interactions and Successful Aging, in Handbook on Animal Assisted Therapy: Theoretical Foundations and Guidelines for Practice, A.H. Fine, Editor. Elsevier Academic Press: San Diego. 2006; 287-302.

[7] Johansson, N. and M. Anderson, Hälsofrämjande effekter av sällskapsdjur - En litteraturstudie. Sektionen för Hälsa och Samhälle: Halmstad. 2005. 
[8] McNicholas, J. and G. Collis, Animals as Social Supports: Insights for Understandig AAT, in Handbook on Animal Assisted Therapy: Theoretical Foundations and Guidelines for Practice, A.H. Fine (ed). Elsevier Academic Press: San Diego. 2006 ; $49-72$.

[9] Nimer, J. and B. Lundahl, Animal Assisted Therapy: A Meta-Analysis. Anthrozoös. 2007; 20(3): 225-238. http://dx.doi.org/10.2752/089279307X224773

[10] Wisdom, J.P., C.A. Green, and G.A. Saedi, Another Breed of "Service" Animals: STARS Study Findings About Pet Ownership and Recovery From Serious Mental Illness. American Journal of Orthopsychiatry. 2009; 79(3): 430-436. PMid:19839680 http://dx.doi.org/10.1037/a0016812

[11] Wang, X. and R.H. Tedford, Evolutionary History of Canids, in The Behavioural Biology of Dogs P. Jensen, (e.) CAB International: Oxfordshire. 2007; 3-10.

[12] Pongrácz, P., et al., Human Listeners Are Able to Classify Dog (Canis familiaris) Barks Recorded in Different Situations. Journal of Comparative Psychology. 2005; 119(2): 136-144. PMid:15982157 http://dx.doi.org/10.1037/0735-7036.119.2.136

[13] Soproni, K., et al., Comprehension of Human Communicative Signs in Pet Dogs (Canis familiaris). Journal of Comparative Psychology. 2001; 115(2): 122-126. PMid:11459158 http://dx.doi.org/10.1037/0735-7036.115.2.122

[14] Mills, D., et al., Left gaze bias in humans, rhesus monkeys and domestic dogs. Animal Cognition. 2009; $12(3): 409-418$. PMid:18925420 http://dx.doi.org/10.1007/s10071-008-0199-3

[15] Kruger, K.A. and J.A. Serpell, Animal Assisted Intervention in Mental Health: Definitions and Theoretical Foundations, in Handbook on Animal Assisted Therapy: Theoretical Foundations and Guidelines for Practice, A.H. Fine, (ed.). Elsevier Academic Press: San Diego. 2006; 21-38.

[16] Miller, S.C., et al. An Examination of Changes in Oxytocin Levels in Men and Women Before and After Interacting with a Bonded Dog. Anthrozoös. 2009; 22(1): 31-42. http://dx.doi.org/10.2752/175303708X390455

[17] Nagasawa, M., K. Mogi, and T. Kikusui. Attachment between humans and dogs. Japanese Psychological Research. 2009; 51(3): 209-221. http://dx.doi.org/10.1111/j.1468-5884.2009.00402.x

[18] Polit, D.F. and C.T. Beck, Essentials of Nursing Research: Appraising Evidence for Nursing Practice. 7th ed., Philadelphia: Wolters Kluwer Health: Lippincott Williams \& Wilkins. 2010.

[19] Jacobsen, D.I., Forståelse, beskrivelse og forklaring - Innføring i samfunnsvitenskapelig metode for helse- og sosialfagene. 1st ed. Kristiansand: Høyskoleforlaget. 2003.

[20] Helseforskningsloven, Lov om medisinsk og helsefaglig forskning m.v. (Helseforskningsloven). 2008.

[21] Simonsen, S. and M. Nylenna, Helseforskningsrett - Den rettslige regulering av medisinsk og helsefaglig forskning., Oslo: Gyldendal Akademisk. 2005.

[22] Malterud, K., Kvalitative Metoder i Medisinsk Forskning. 2.nd ed., Oslo: Universitetsforlaget. 2003.

[23] Fugelli, P. and B. Ingestad, A lay perspective on health. Tidsskrift for den Norske Lægeforeningen. 2001; 121: $3600-3604$.

[24] Hamer, M., E. Stamatakis, and A. Steptoe, Dose-response relationship between physical activity and mental health: the Scottish Health Survey. British Journal of Sports Medicin. 2009; 43: 1111-1114. PMid:18403415 http://dx.doi.org/10.1136/bjsm.2008.046243

[25] Dahl, A.A. and M. Wiborg, Er sosial angst noe å bry seg om? Tidsskrift for den Norske Lægeforeningen. 2010; 130: $288-290$.

[26] Cullberg, J., Dynamisk Psykiatri. 5.th ed., Stockholm: Tano Aschehoug. 1999; 576.

[27] Norwegian Kennel Club, Norwegian Kennel Club's Etical Guidelines on dogkeeping [Internet]. Norwegian Kennel Club. 2010. Available from: http://www.nkk.no/nkk/public/openIndex?ARTICLE_ID=9396. p. 8.

[28] Fine, A.H., Incorporating Animal-Assisted Therapy into Psychotherapy: Guidelines and Suggestions for Therapists, in Handbook on Animal Assisted Therapy: Theoretical Foundations and Guidelines for Practice, A.H. Fine, (ed.). Elsevier Academic Press: San Diego. 2006; 167-206. 